\title{
GRAPH LABELLING TECHNIQUES
}

\author{
DUSHYANT KIRITBHAI TANNA
}

(Received 5 June 2018; first published online 15 August 2018)

2010 Mathematics subject classification: primary 05C78.

Keywords and phrases: graph theory, graph labelling.

We begin by giving some background to some of the more well known labelling schemes like graceful, harmonious, magic, antimagic and irregular total labellings. Following this, we give some preliminary results and open problems in these schemes. Irregular total labellings were introduced by Bača et al. [1]. We introduce a new branch of irregular total labelling-irregular reflexive labelling.

This new labelling technique is a variation on total irregular labelling with a modification of the vertex labels. In particular:

- the vertex labels are nonnegative even integers;

- the vertex label 0 is permissible, representing the vertex without loop.

The vertex (edge) irregular reflexive labelling is a total labelling with the above conditions on the vertex labels such that the vertex (edge) weights are distinct. The idea is to use the minimum possible labels for the vertices (edges) and thus keep the reflexive vertex (edge) strength as low as possible. We believe that this new technique is closer in concept to the original irregular labelling as proposed by Chartrand et al. [3], since the vertex labels are also being used to represent edges (loops).

Again, the objective is to minimise the total strength by restricting the maximum vertex (edge) label to be as small as possible. We give edge and vertex irregular reflexive strengths for many graphs such as paths, cycles, stars, complete graphs, prisms, wheels, baskets, friendship graphs, joins of graphs and generalised friendship graphs. Our methods are constructive in that we also present labelling techniques for these graphs.

In later chapters we return to antimagic labelling. We describe edge covering, $H$ edge covering, $H$-magic and $H$-antimagic graphs and prove some theorems based on

Thesis submitted to the University of Newcastle in June 2017; degree approved on 4 December 2017; supervisors Mirka Miller, Joe Ryan, Thomas Kalinowski, Andrea Semaničová-Feňovčiková and Jonathan Borwein.

(C) 2018 Australian Mathematical Publishing Association Inc. 
these concepts. We use the partitions of a set of integers with determined differences $d$, as introduced by Bača et al. [2], to construct $H$-antimagic labellings of certain graphs. If the graph $G^{H}$ is super $(a, d)$ - $H$-antimagic, we use the upper bound of the difference $d$ to establish a connection between $H$-antimagic labellings and edge-antimagic total labellings.

Finally, we address why the study of graph labelling is important by explaining some applications of graph labelling and give some open problems and conjectures.

\section{References}

[1] M. Bača, S. Jendrol', M. Miller and J. Ryan, 'Total irregular labelings', Discrete Math. 307 (2007), 1378-1388.

[2] M. Bača, M. Miller, O. Phanalasy and A. Semaničová-Feňovčiková, 'Constructions of antimagic labelings for some families of regular graphs', J. Algorithms Comput. 44 (2013), 1-7.

[3] G. Chartrand, M. S. Jacobson, J. Lehel, O. R. Oellermann, S. Ruiz and F. Saba, 'Irregular networks', Congr. Numer. 64 (1988), 187-192.

DUSHYANT KIRITBHAI TANNA,

School of Mathematical and Physical Sciences,

University of Newcastle, Callaghan, NSW 2308, Australia

e-mail: dtanna.vmgbr@gmail.com 